\title{
Atypical presentation of lymphomatoid granulomatosis in a patient with longstanding sarcoidosis
}

\author{
Paul S Koh MD ${ }^{1}$, Annette HC Foyle MD CM FRCPC 2 , Yannick Cartier MD FRCPC ${ }^{3}$, G Ross Langley MD FRCPC ${ }^{4}$, \\ Nancy J Morrison MD FRCPC ${ }^{5}$, Graeme Rocker MA MHSC DM FRCPC ${ }^{5}$, Alan G Casson FRCSC ${ }^{1}$
}

PS Koh, AHC Foyle, Y Cartier, et al. Atypical presentation of lymphomatoid granulomatosis in a patient with longstanding sarcoidosis. Can Respir J 2004;11(1):51-54.

A patient was recently evaluated who had longstanding sarcoidosis with lymphadenopathy and multiple, small lung nodules, and who developed a new, $9 \mathrm{~cm}$ solitary pulmonary mass in the right lower lobe. After thoracotomy, this lesion was ultimately found to be lymphomatoid granulomatosis, a rare lymphoproliferative disorder. Radiographic evaluations of patients with this disorder characteristically show multiple, bilateral reticulonodular opacities that follow the bronchovascular bundles; however, presentation with a solitary, large pulmonary mass is rare. The present case illustrates the need for complete evaluation of new clinical and radiographic findings in the setting of chronic lung disease.

Key Words: Angiocentric lymphoma; Hematological malignancies; Lymphomatoid granulomatosis; Pulmonary lesions; Sarcoidosis

\section{Manifestation atypique d'une granulomatose lymphoïde chez un patient atteint de sarcoïdose ancienne}

Un patient atteint de sarcoïdose ancienne, accompagnée d'adénopathie et d'une multitude de petits nodules pulmonaires, a été examiné récemment pour l'apparition d'une nouvelle masse isolée, de $9 \mathrm{~cm}$, dans le lobe inférieur droit. Il s'est avéré, après thoracotomie, qu'il s'agissait d'une granulomatose lymphoïde, trouble lympho-prolifératif rare. L'image radiologique typique de ce trouble montre de nombreuses taches réticulonodulaires bilatérales, suivant le trajet des faisceaux broncho-vasculaires, mais il est rare que la maladie se manifeste sous la forme d'une grosse masse pulmonaire isolée. Le présent cas illustre bien la nécessité de procéder à une évaluation complète de nouvelles observations cliniques et radiologiques dans les cas de pneumopathie chronique.
Carcoidosis is the most prevalent granulomatous disease, $\checkmark$ with frequent involvement of the lung. Patients usually present with a dry cough, dyspnea and occasional constitutional symptoms (1). Radiographic features are variable and are better demonstrated by high resolution computed tomography (HRCT) than by a plain chest radiograph. Characteristic findings on HRCT, seen in about $70 \%$ of patients, include bilateral, symmetrical hilar and mediastinal lymphadenopathy - with or without associated pulmonary parenchymal involvement - of which multiple, small (usually less than $1 \mathrm{~cm}$ ) perilymphatic nodules are most often seen. Additional pulmonary parenchymal abnormalities include ground-glass opacification, consolidation, areas of fibrosis and, rarely, larger nodules of up to $4 \mathrm{~cm}$ in diameter (2).

We recently evaluated a patient with longstanding sarcoidosis who presented with a new, $9 \mathrm{~cm}$ pulmonary mass in the right lower lobe. This mass was ultimately diagnosed as grade III lymphomatoid granulomatosis, an unusual lymphoproliferative lesion. The present report describes this unique presentation of an uncommon malignancy and emphasizes the need for complete evaluation of new clinical and radiographic findings in the setting of chronic lung disease.

\section{CASE PRESENTATION}

A 45-year-old man presented in March 1998 to his family physician with mild dyspnea and a dry cough. There were no other significant symptoms. The patient was a nonsmoker and was otherwise healthy. Physical examination revealed coarse breath sounds over the right lung and scattered wheezes bilaterally. A chest radiograph and HRCT showed bilateral parenchymal nodules measuring less than $1 \mathrm{~cm}$ in diameter, in addition to calcified bilateral hilar and mediastinal lymph nodes.

The patient was referred to respirology and a clinical diagnosis of sarcoidosis was made. Initial pulmonary function tests were unremarkable (forced expiratory volume in $1 \mathrm{~s}\left[\mathrm{FEV}_{1}\right] 4.01$ [87\%], forced vital capacity [FVC] 5.68 [98\%], diffusion capacity of the lung for carbon monoxide [DLCO] $82 \%$ ). He remained clinically stable until February 2000, when he noted increasing dyspnea. Pulmonary function testing showed deterioration in diffusing capacity and evidence of moderate air flow obstruction ( $\mathrm{FEV}_{1} 2.69$ [59\%], FVC 3.97 [69\%], DLCO 65\%). Despite high dose inhaled steroids, his symptoms failed to improve. He was prescribed oral prednisone with noticeable subjective and objective improvement $\left(\mathrm{FEV}_{1} 3.09\right.$ [68\%], FVC 4.67 [81\%], DLCO 76\%). Radiographic studies showed no

${ }^{1}$ Division of Thoracic Surgery, ${ }^{2}$ Department of Pathology, ${ }^{3}$ Department of Radiology, ${ }^{4}$ Division of Hematology, ${ }^{5}$ Division of Respirology,

Dalhousie University and the Queen Elizabeth II Health Sciences Centre, Halifax, Nova Scotia

Correspondence and reprints: Alan G Casson, Division of Thoracic Surgery, Queen Elizabeth II Health Sciences Centre, Victoria Building 7S-008,

1278 Tower Road, Halifax, Nova Scotia B3H 2Y9. Telephone 902-473-2281, fax 902-473-4426, e-mail alan.casson@dal.ca 


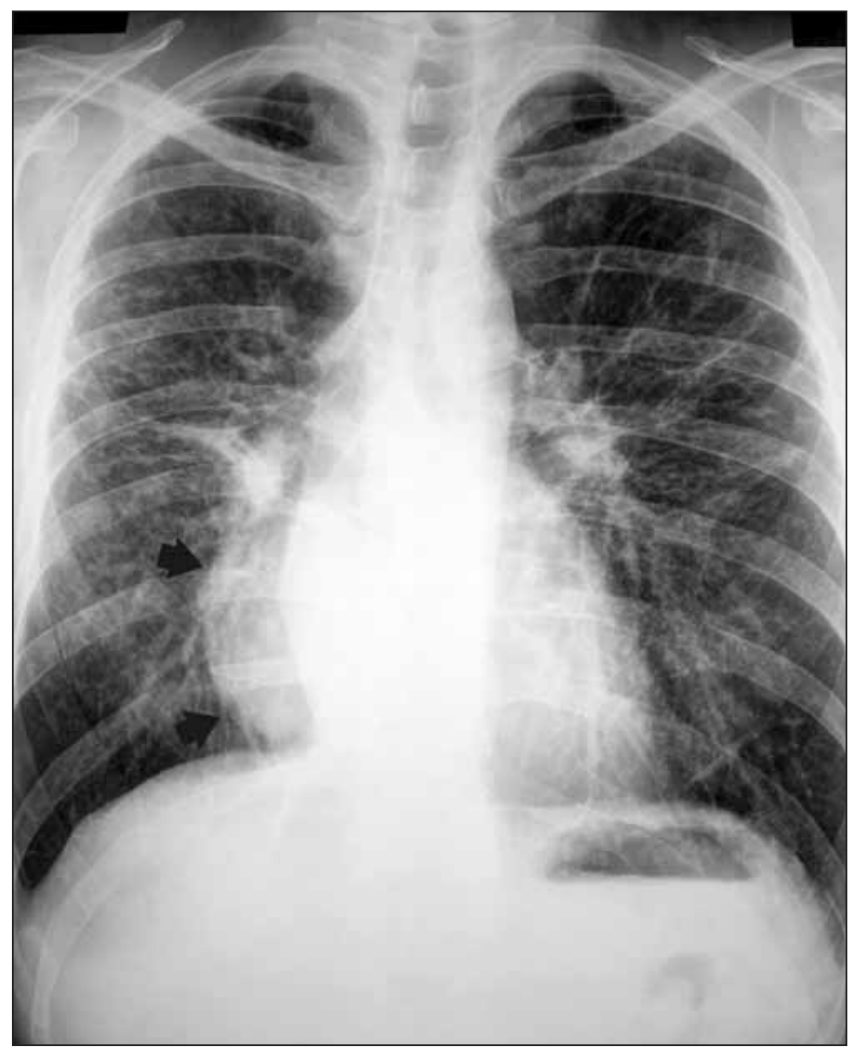

Figure 1) Plain chest radiograph (posteroanterior view) demonstrating a well-defined mass in the retrocardiac region (arrows) measuring $9 \mathrm{~cm}$ in diameter. Chronic bilateral hilar lymph node enlargement and small pulmonary parenchymal nodules are also seen

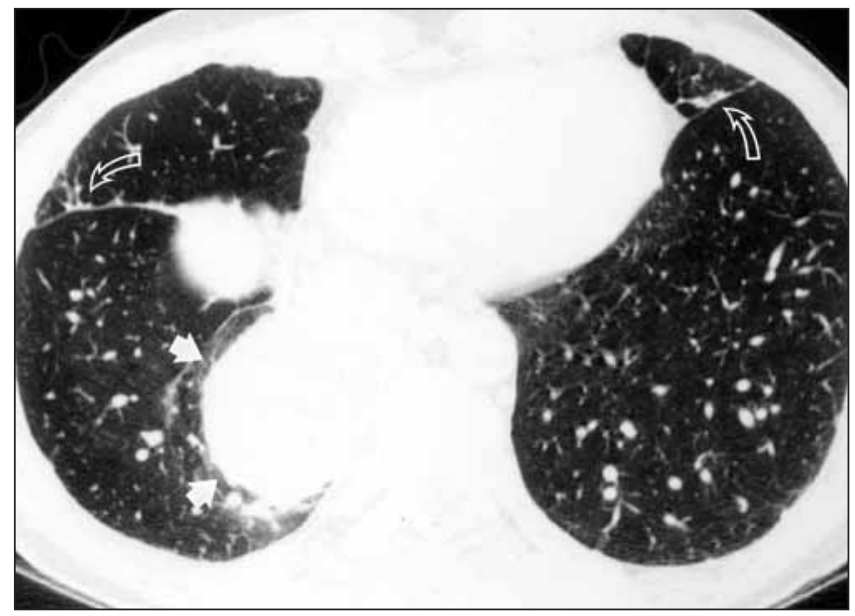

Figure 2) Targeted thin collimation (1 $\mathrm{mm}$ ) computed tomography demonstrating a well-defined solid mass medial to the right lower lobe (solid arrows). Fine nodularity (curved open arrows) was also seen along the right and left major fissures

interval change. Attempts to discontinue prednisone resulted in further exacerbation of his respiratory symptoms.

In 2001, he developed pain in the right lower chest wall, with accompanying night sweats and fatigue. A physical examination and laboratory evaluation were unremarkable. A chest radiograph demonstrated a new mass in the right retrocardiac region, in addition to multiple, small pulmonary parenchymal nodular

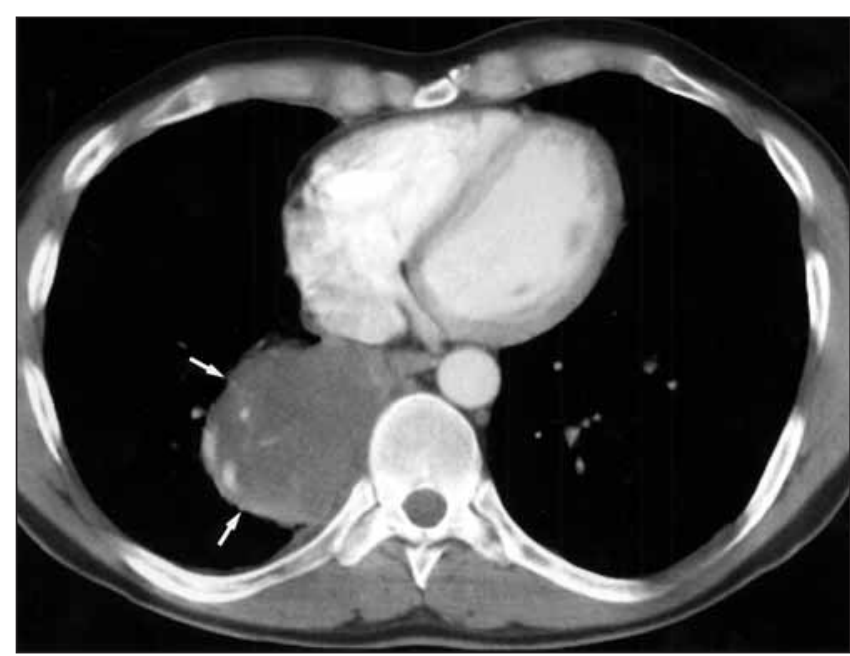

Figure 3) Enhanced spiral computed tomography (mediastinal windows) demonstrating that the mass is of soft tissue density, with extensive areas of low attenuation, compatible with necrosis (arrows). The mass abutts the mediastinum medially, displacing the segmental vessels of the right lower lobe laterally

and linear densities, and chronic bilateral hilar lymph node enlargement (Figure 1). Enhanced spiral computed tomography scanning confirmed a solid mass in the right lower lobe (Figures 2 and 3). The mass was in contiguity with the mediastinum and the right infrahilar region. Calcified bilateral hilar and mediastinal lymph nodes were also present and unchanged since 1998.

The patient was referred to thoracic surgery to obtain a definitive tissue diagnosis, and the patient proceeded directly to thoracotomy. The patient had extensive mediastinal lymphadenopathy. Lymph nodes were sampled extensively, and no evidence of malignancy was found on frozen section. The firm, $9 \mathrm{~cm}$ mass appeared to arise within the right lower lobe and was densely adherent to the inferoposterior mediastinum, from which it was successfully mobilized. Because a wedge resection was not technically feasible, the patient underwent right lower lobectomy.

\section{Histopathology}

Histology of the right lower lobe mass showed extensive necrosis, with a polymorphic, dense cellular infiltrate composed of medium to large lymphocytes, immunoblasts, plasma cells and histiocytes, with scattered large atypical ReedSternberg-like cells (Figure 4). The neoplasm showed angiocentricity and angiodestruction (Figure 5). CD20 immunohistochemical staining revealed sheets of large B cells (Figure 4, inset), including the atypical Reed-Sternberg-type cells. Numerous CD4+ T cells and scattered CD8+ cells were demonstrated. In situ hybridization studies of the tumour cells for Epstein-Barr virus (EBV) using the Epstein-Barr-encoded small RNA-1 probe were uniformly positive. These findings were diagnostic of diffuse, large B cell angiocentric lymphoma, consistent with grade III lymphomatoid granulomatosis. The mediastinal lymph nodes contained noncaseating granulomas consistent with sarcoidosis. Numerous granulomas were seen throughout the lung parenchyma with a characteristic lymphangitic distribution. 


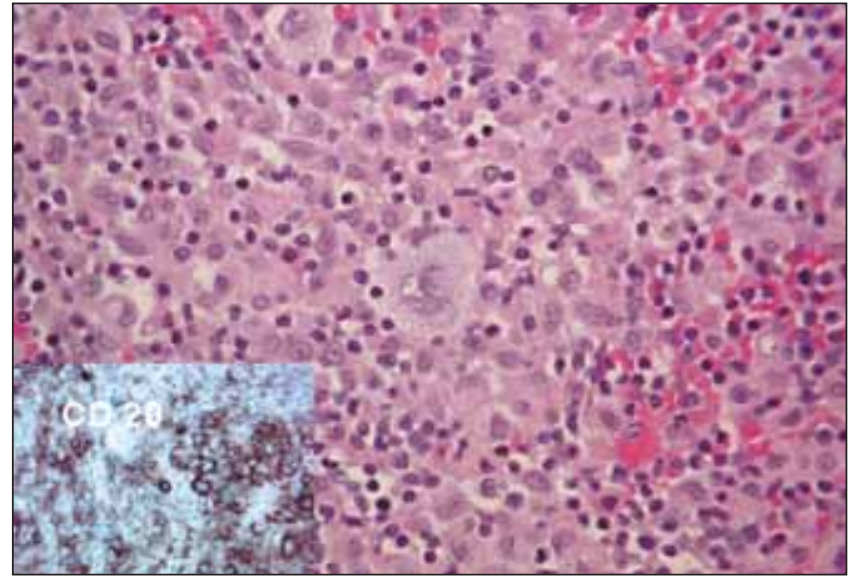

Figure 4) Hematoxylin and eosin stain of the resected mass, showing a polymorphous infiltrate of histiocytes, small lymphocytes and large lymphoid cells, with Reed-Sternberg-like cells. Inset Immunoreactivity for CD20 (original magnification $\times 500$ )

\section{Clinical course}

The patient was referred to hematology. Staging evaluations for lymphoma did not indicate any other sites of disease. Combination chemotherapy with cyclophosphamide, doxorubicin, vincristine and prednisone is ongoing.

\section{DISCUSSION}

Lymphoproliferative lesions, which have a characteristic predilection toward angiocentricity and angiodestruction, were first described by Liebow et al (3), who coined the term lymphomatoid granulomatosis to denote similarities in morphology and clinical behaviour to both Wegener's granulomatosis and malignant lymphoma. Lymphomatoid granulomatosis presents primarily with symptoms of pulmonary involvement such as cough and dyspnea, frequently accompanied by fatigue, fever and night sweats (4). Radiographs characteristically show multiple, bilateral reticulonodular opacities that follow the bronchovascular bundles (5). The occasional patient will have larger nodules or cavitary lesions (4). Mediastinal lymphadenopathy is distinctly uncommon (6). Clinical and pathological studies have also demonstrated variable degrees of involvement of the kidneys, liver, central nervous system, bone marrow and eyes (7). Lymphomatoid granulomatosis does not have any known association with granulomatous diseases, including sarcoidosis. In a larger clinicopathological series, only one patient was noted to have coexistent sarcoidosis (8). Lymphomatoid granulomatosis may, however, be associated with other immunodeficiency disorders, including acquired immune deficiency syndrome and Wiskott-Aldrich syndrome, as well as following transplantation.

Diagnosis is generally made by wedge biopsy of the lung. Nodules consist of a polymorphous cellular infiltrate consisting of mature lymphocytes, plasma cells, histiocytes and atypical lymphoreticular cells containing multilobed nuclei and prominent basophilic nucleoli $(6,8)$. This cellular proliferation shows characteristic infiltration into branches of the pulmonary arteries and veins. Immunophenotypic studies have shown that most of the proliferating lymphocytes are post-thymic, CD4-positive $\mathrm{T}$ cells (9). However, Guinee and colleagues (10) have shown

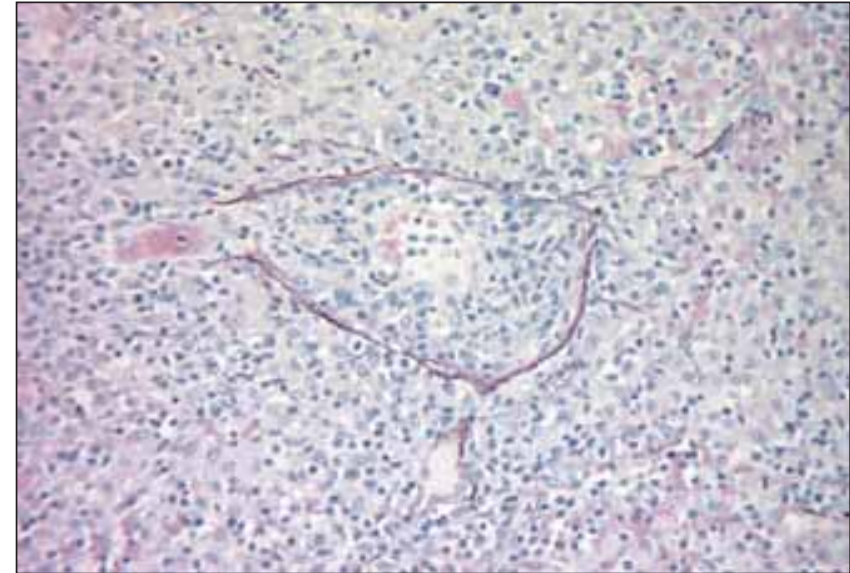

Figure 5) Orcein Giemsa stain for elastic fibres, demonstrating angioinfiltration by polymorphous histiocytes, small lymphocytes and large lymphoid cells (original magnification $\times 500$ )

that there is also a population of larger lymphocytes and atypical cells that are of B cell lineage, and recent molecular studies have demonstrated a monoclonal or oligoclonal population of B lymphoid cells $(11,12)$. Molecular situ hybridization studies on these lymphocytes have shown EBV sequences within these $B$ cell populations, and uniform absence of EBV in the T cells. It is hypothesized that lymphomatoid granulomatosis involving the lung represents a proliferation of EBV-infected B cells, with a secondary $\mathrm{T}$ cell-mediated vasculitis, which may have some analogy to EBV-associated post-transplantation B lymphoproliferative disorders (10).

The degree of atypia seen in lymphomatoid granulomatosis ranges from a cytologically mature variant that has been termed 'benign lymphocytic angiitis and granulomatosis', to lesions with markedly atypical features consistent with malignancy $(8,13,14)$. Clinical data support the cytologically implicit potential for progression of these lesions to frank lymphoma. Katzenstein and colleagues (8) noted a direct correlation between the number of atypical lymphoreticular cells and mortality. In their retrospective review, 13\% of patients were diagnosed with lymphoma. In a prospective series from the National Institutes of Health (7), seven of 15 patients (47\%) treated for lymphomatoid granulomatosis developed lymphoma over a 10-year period.

The alternative term, angiocentric immunoproliferative lesion (AIL), was previously used to better convey the key features of the spectrum of lymphoid diseases (15). Lipford and colleagues (9) applied a histological grading system to AILs to guide clinical management. Grade I lesions were those with no significant cytological atypia. Grade II lesions featured some degree of cytological atypia in small lymphoid cells, but had only occasional large lymphoid cells. Grade III AILs had marked atypia and necrosis, and were felt to be malignant lymphomas by cytological criteria; these lesions were termed angiocentric lymphomas. Grade I and II lesions were initially treated with low dose cyclophosphamide and prednisone. Eight of the 15 patients in Lipford et al's study (9) achieved a complete and durable remission. The seven remaining patients progressed to malignant lymphoma and only one achieved a complete 
remission when treated with combination chemotherapy. Grade III lesions were treated with aggressive combination chemotherapy, and seven of eight patients achieved a complete remission. This study emphasizes the malignant potential of even low grade lesions, as well as the prognostic importance of achieving an initial complete remission. Overall mortality for series of patients with lymphomatoid granulomatosis is reported to range from $34 \%$ to $63 \%(6-8)$.

The initial clinical presentations for sarcoidosis and lymphomatoid granulomatosis are generally similar. Both diseases feature nonspecific pulmonary complaints and constitutional symptoms. The two conditions often have similar radiographic findings, comprising of bilateral, ill-defined reticular or nodular parenchymal densities. Differentiating features include the presence of prominent hilar and mediastinal lymphadenopathy in sarcoidosis, and a tendency toward larger and more welldefined nodules in lymphomatoid granulomatosis. The presence of a dominant, unilateral chest mass is unusual for both

\section{REFERENCES}

1. Crystal RG. Sarcoidosis. In: Isselbacher KJ, Braunwald E, Wilson JD, et al, eds. Harrison's Principles of Internal Medicine. New York: McGraw-Hill, 1994:1679-84.

2. Lange S, Walsh G. Inflammatory Disorders. Radiology of Chest Diseases. New York: Thieme, 1998:95-9.

3. Liebow AA, Carrington CB, Friedman PJ. Lymphomatoid granulomatosis. Hum Pathol 1972;3:457-558.

4. Dee PM, Arora NS, Innes DJ Jr. The pulmonary manifestations of lymphomatoid granulomatosis. Radiology 1982;143:613-8.

5. Lee JS, Tuder R, Lynch DA. Lymphomatoid granulomatosis: Radiologic features and pathologic correlations. AJR Am J Roentgenol 2000;175:1335-9.

6. Koss MN, Hochholzer L, Langloss JM, et al. Lymphomatoid granulomatosis: A clinicopathologic study of 42 patients. Pathology 1986;18:283-8.

7. Fauci AS, Haynes BF, Costa J, et al. Lymphomatoid granulomatosis. Prospective clinical and therapeutic experience over 10 years. N Engl J Med 1982;306:68-74.

8. Katzenstein AL, Carrington CB, Liebow AA. Lymphomatoid granulomatosis: A clinicopathologic study of 152 cases. Cancer 1979;43:360-73. sarcoidosis and lymphomatoid granulomatosis. Prednisone also has a salutary effect on both disease processes.

\section{CONCLUSIONS}

As illustrated by the present report, the finding of a new radiographic lesion in a patient with longstanding, chronic lung disease requires a thorough diagnostic evaluation. The differential diagnosis is diverse, and includes both benign and malignant etiologies. Lymphomatoid granulomatosis is uncommon, and its atypical presentation as a single, unilateral, dominant mass is rare. We feel that proceeding directly to thoracotomy and pulmonary resection expedited treatment for this unusual malignancy. Early establishment of the definitive diagnosis of angiocentric lymphoma facilitated the initiation of combination chemotherapy for this aggressive lymphoproliferative lesion. Based on our final histological findings, it is unlikely that less invasive investigations, such as percutaneous fine needle or core needle biopsy, would have been diagnostic.

9. Lipford EH Jr, Margolick JB, Longo DL, et al. Angiocentric immunoproliferative lesions: A clinicopathologic spectrum of post-thymic T-cell proliferations. Blood 1988;72:1674-81.

10. Guinee D Jr, Jaffe E, Kingma D, et al. Pulmonary lymphomatoid granulomatosis. Evidence for a proliferation of Epstein-Barr virus infected B-lymphocytes with a prominent T-cell component and vasculitis. Am J Surg Pathol 1994;18:753-64.

11. Israel HL, Patchefsky AS, Saldana MJ. Wegener's granulomatosis, lymphomatoid granulomatosis, and benign lymphocytic angiitis and granulomatosis of lung. Recognition and treatment. Ann Intern Med 1977;87:691-9.

12. Wilson WH, Kingma DW, Raffeld M, Wittes RE, Jaffe ES. Association of lymphomatoid granulomatosis with Epstein-Barr viral infection of B lymphocytes and response to interferon-alpha $2 \beta$. Blood 1996;87:4531-7.

13. Jaffe ES, Wilson WH. Lymphoid granulomatosis: Pathogenesis, pathology and clinical implications. Cancer Surv 1997;30:233-48.

14. Weiss MA, Rolfes DB, Alvira MA, et al. Benign lymphocytic angiitis and granulomatosis: A case report with evidence of an autoimmune etiology. Am J Clin Pathol 1984;81:110-6.

15. Jaffe ES. Pathologic and clinical spectrum of post-thymic T-cell malignancies. Cancer Invest 1984;2:413-26. 


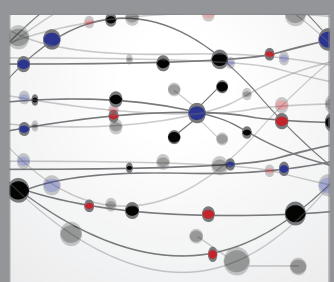

The Scientific World Journal
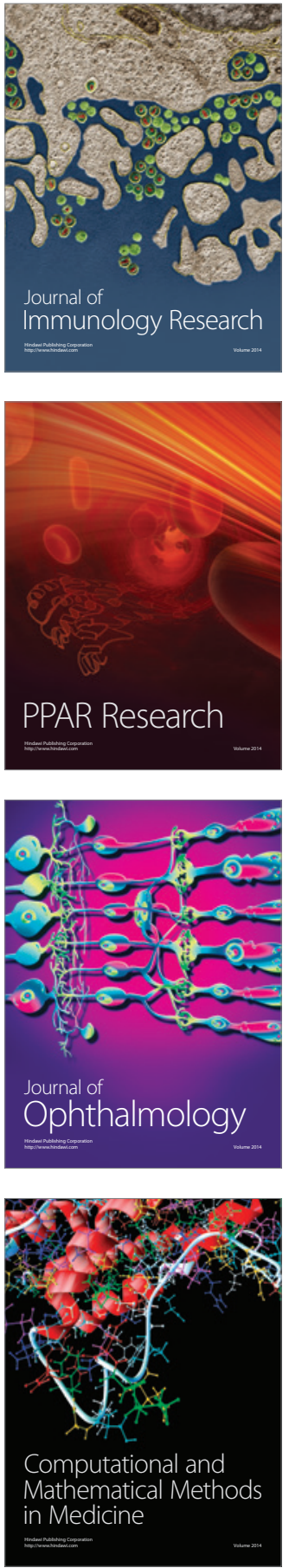

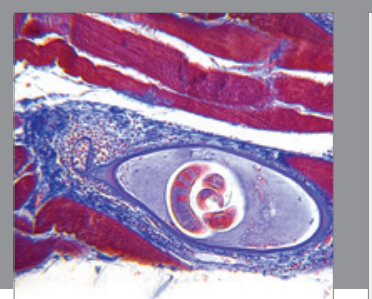

Gastroenterology Research and Practice

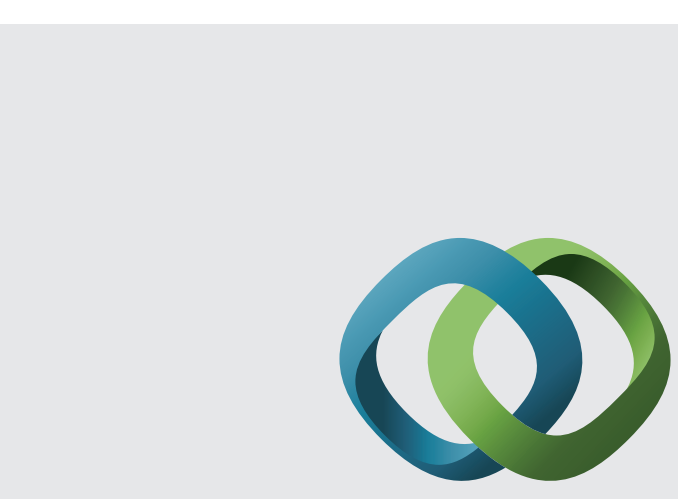

\section{Hindawi}

Submit your manuscripts at

http://www.hindawi.com
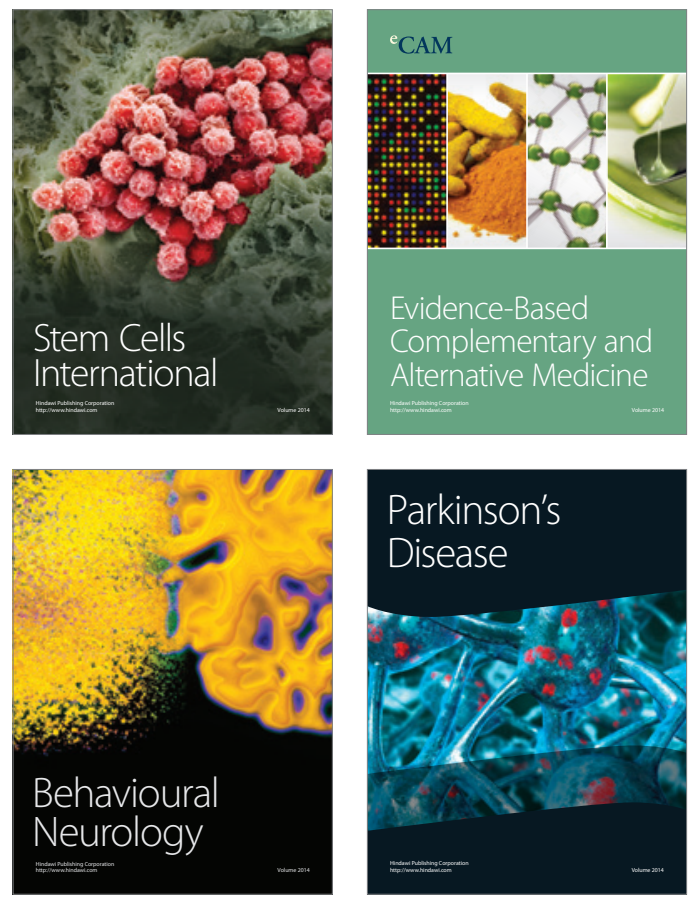
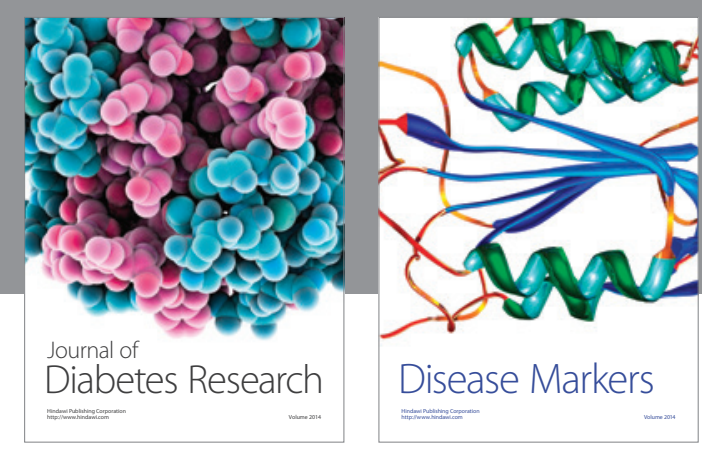

Disease Markers
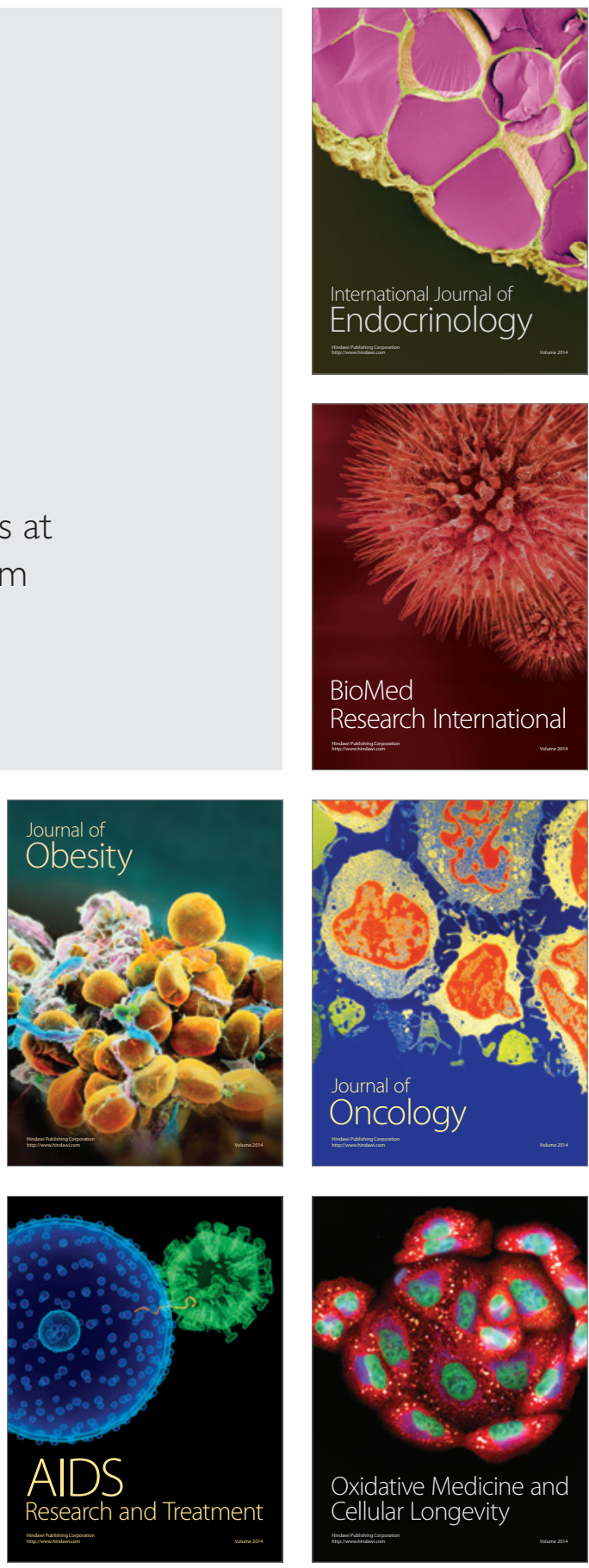